Baseline

\title{
A comparative proteomic study on the effects of metal pollution in oysters Crassostrea hongkongensis
}

\author{
Lanlan $\mathrm{Xu}^{\mathrm{a}, \mathrm{b}}$, Chenglong Ji ${ }^{\mathrm{a}}$, Huifeng $\mathrm{Wu}^{\mathrm{a}, *}$, Qiaoguo Tan ${ }^{\mathrm{c}}$, Wen-Xiong Wang ${ }^{\mathrm{d}}$

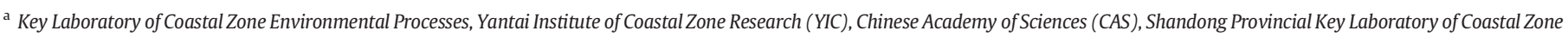 \\ Environmental Processes, YICCAS, Yantai 264003, P.R. China \\ ${ }^{\mathrm{b}}$ University of Chinese Academy of Sciences, Beijing 100049, P.R. China \\ ${ }^{\mathrm{c}}$ Key Laboratory of the Coastal and Wetland Ecosystems, Ministry of Education, College of Environment and Ecology, Xiamen University, Xiamen 361102, P.R. China \\ d Division of Life Science, The Hong Kong University of Science and Technology (HKUST), Clearwater Bay, Kowloon, Hong Kong
}

\section{A R T I C L E I N F O}

\section{Article history:}

Received 12 June 2016

Received in revised form 4 July 2016

Accepted 6 July 2016

Available online $\mathrm{xxxx}$

\section{Keywords:}

Metal pollution

Crassostrea hongkongensis

Hepatopancreas

Proteomics

\begin{abstract}
A B S T R A C T
The metal pollution has posed great risk on the coastal organisms along the Jiulongjiang Estuary in South China. In this work, two-dimensional electrophoresis-based proteomics was applied to the oysters Crassostrea hongkongensis from metal pollution sites to characterize the proteomic responses to metal pollution. Metal accumulation and proteomic responses indicated that the oysters from BJ site were more severely contaminated than those from FG site. Compared with those oyster samples from the clean site (JZ), metal pollution induced cellular injuries, oxidative and immune stresses in oyster heapatopancreas from both BJ and FG sites via differential metabolic pathways. In addition, metal pollution in BJ site induced disturbance in energy and lipid metabolisms in oysters. Results indicated that cathepsin L and ferritin GF1 might be the biomarkers of As and Fe in oyster C. hongkongensis, respectively. This study demonstrates that proteomics is a useful tool for investigating biological effects induced by metal pollution.
\end{abstract}

(c) 2016 Elsevier Ltd. All rights reserved.
Metal pollution in the estuarine and coastal environments in South China has posed a significant threat to coastal organisms (Luo et al., 2014; Wang et al., 2014). Previous researches reported that the oysters Crassostrea hongkongensis and Crassostrea sikamea from the metal-polluted sites along the Jiulongjiang Estuary, Fujian Province, were severely contaminated by copper, which was marked by the blue or green tissues in oysters with the high tissue $\mathrm{Cu}$ concentration up to $19,000 \mu \mathrm{g} / \mathrm{g}$ dry weight (Weng and Wang, 2014). Therefore, it is necessary to elucidate the biological effects induced by metal pollution, which may be further used to predict the consequence of metal pollution.

As a marine filter-feeder, oysters are not only edible bivalves but play an important role in maintaining the marine ecosystem health in many estuarine systems (Weng and Wang, 2014). Due to its high capacity to accumulate metals, oysters such as Crassostrea hongkongensis, Crassostrea sikamea and Saccostrea glomerata are also preferable environmental bioindicators for metals (Goldberg et al., 1983). Thompson et al. (2011) used Sydney rock oyster Saccostrea glomerata as the bioindicator to investigate the effects of metals including $\mathrm{Cd}, \mathrm{Cu}, \mathrm{Zn}$ and $\mathrm{Pb}$, which suggested that this oyster was a good bioindicator of metal pollution. Evidences have indicated that the oyster $C$. hongkongensis distributed along the coast in South China is a hyperaccumulator of $\mathrm{Cu}$ and $\mathrm{Zn}$ (Tan et al., 2015). In this study,

\footnotetext{
* Corresponding author.

E-mail address: hfwu@yic.ac.cn (H.Wu).
}

therefore, the oyster $C$. hongkongensis was selected to investigate the biological effects of metal pollution.

Using toxicity-related biomarkers of metals, such as the anti-oxidative enzyme activities and metallothioneins, to monitor metal pollution has been accepted in ecotoxicology and environmental monitoring programs (Regoli, 2000; Rank et al., 2007). Among these established biomarkers, however, few of them have adequate sensitivity, specificity and predictability for metal pollution. With the rapid development of omic techniques, researchers can carry out a global analysis on the molecules to obtain a set of biomarkers related to the biological effects induced by metal pollution, which facilitates the detection and prediction of metal pollution (Cappello et al., 2013; Knigge et al., 2004). Among these -omic techniques, proteomics can theoretically analyze all the proteins encoded by the given genome in an organism (Knigge et al., 2004). Therefore, a comparative proteomics may compare the whole protein profiles in the selected environmental bioindicators from normal and metal pollution-stressed conditions and present the proteomic differences induced by metal pollution. Based on its applicability in ecotoxicology and environmental biology, comparative proteomics has been used as a diagnostic tool for environmental pollution assessment (Campos et al., 2012).

In this study, we applied two-dimensional electrophoresis (2-DE)based proteomics to investigate the proteomic responses in oyster (Crassostrea hongkongensis) to metal pollution. The oysters $C$. hongkongensis were collected from three sites (Baijiao, Fugong and 
Jiuzhen) along the Jiulongjiang Estuary, Fujian Province, China. Among these sampling sites, the former two sites were contaminated by different concentrations of metals (such as copper, zinc, cadmium and iron), respectively. The Jiuzhen site was a relatively clean and used as a reference. The hepatopancreas tissues of oysters were collected for metal analysis and proteomics, as the hepatopancreas tissue is the main storage and detoxification organ for metals (Jones et al., 2008). The aims of this study were to characterize the proteomic responses and biological effects in oysters $C$. hongkongensis exposed to metal pollution using 2DE-based proteomics.

During the low tides, the contaminated oysters $C$. hongkongensis were collected from Baijiao (BJ, $24^{\circ} 28^{\prime} 2^{\prime \prime} \mathrm{N}, 117^{\circ} 56^{\prime} 19^{\prime \prime} \mathrm{E}$ ) and Fugong (FG, $24^{\circ} 22^{\prime} 58^{\prime \prime} \mathrm{N}, 117^{\circ} 54^{\prime} 13^{\prime \prime} \mathrm{E}$ ) sites along the contaminated Jiulongjiang Estuary, and the control oysters were collected from the harbor of Jiuzhen ( $\left.\mathrm{JZ}, 24^{\circ} 2^{\prime} 38^{\prime \prime} \mathrm{N}, 117^{\circ} 42^{\prime} 26^{\prime \prime} \mathrm{E}\right)$ site from the nearby relatively clean Jiuzhen estuary, Fujian Province, in December 2012 (Fig. 1 ). This estuary was an important area for oyster culture, and the average surface salinity ranged from 14 to $26 \mathrm{psu}$ as for tidal actions (Liu and Wang, 2012). Ten individual oysters with similar sizes were sampled from each site, and the tissues of hepatopancreas were immediately dissected and flash frozen in liquid $\mathrm{N}_{2}$. After transported to the laboratory, the oyster samples were stored at $-80^{\circ} \mathrm{C}$ before protein extraction and metal determination. All the practical procedures for oyster sampling were strictly performed according to the guidelines suggested by Hines et al. (2007).

Total protein extraction was performed based on previous studies with some modifications (Wu et al., 2013a). Briefly, the oyster samples were homogenized quickly on ice with $1 \mathrm{~mL}$ of TRIzol reagent and centrifuged at $12,000 \mathrm{~g}$ for $5 \mathrm{~min}$ at $4{ }^{\circ} \mathrm{C}$. The supernatant was added with $200 \mu \mathrm{L}$ of chloroform before shaking vigorously for $3 \mathrm{~min}$ and precipitating for $3 \mathrm{~min}$. The mixture was centrifuged at $12,000 \mathrm{~g}$ for $15 \mathrm{~min}$ at $4{ }^{\circ} \mathrm{C}$, and its upper aqueous layer was discarded. A volume of $300 \mu \mathrm{L}$ of absolute ethyl alcohol was added and the mixture was allowed to stand for $3 \mathrm{~min}$ at room temperature before being centrifuged at $2000 \mathrm{~g}$ for $5 \mathrm{~min}$ at $4{ }^{\circ} \mathrm{C}$. The phenol/ethanol supernatant was precipitated for $30 \mathrm{~min}$ at room temperature by the addition of $750 \mu \mathrm{L}$ of isopropanol prior to centrifugation at $14,000 \mathrm{~g}$ for $10 \mathrm{~min}$ at $4{ }^{\circ} \mathrm{C}$. The pellets were washed with $1 \mathrm{~mL}$ of ethanol (v/v 95\%) and centrifuged at 14,000g for $10 \mathrm{~min}$ at $4{ }^{\circ} \mathrm{C}$. This procedure was repeated twice. The pellets were solubilized in the lysis buffer ( $7 \mathrm{M}$ urea; $2 \mathrm{M}$ thiourea; $4 \% \mathrm{~m} / \mathrm{V}$ CHAPS; $65 \mathrm{mM}$ DTT and 0.2\% W/V Bio-lyte buffer) and then incubated for $3 \mathrm{~h}$ at room temperature. The homogenate was centrifuged at $15,000 \mathrm{~g}$ for $10 \mathrm{~min}$ and the supernatant was applied to electrophoresis. The total concentrations of proteins were determined by Protein Assay Kit of TianGen.

For the first dimension (IEF), $130 \mu \mathrm{g}$ of protein was loaded onto IPG strips with a linear pH gradient from 4 to 7 (Immobiline Drystrip TM $24 \mathrm{~cm}$, GE Healthcare, USA) The isoelectric focusing gel solution (7 M urea, $2 \mathrm{M}$ thiourea, $4 \% \mathrm{~m} / \mathrm{v}$ CHAPS, $65 \mathrm{mM} \mathrm{DTT}, 0.001 \% \mathrm{~m} / \mathrm{v}$ bromophenol blue and $0.2 \% \mathrm{~W} / \mathrm{V}$ Bio-lyte buffer). IEF was conducted at $20^{\circ} \mathrm{C}$ with an Ettan IPGphor3 system for a total of 85,858 Vh (active rehydration was carried out at $30 \mathrm{~V}$ for $12 \mathrm{~h}$, followed by $100 \mathrm{~V}$ for $5 \mathrm{~h}, 500 \mathrm{~V}$ for $1 \mathrm{~h}, 1000 \mathrm{~V}$ for $1 \mathrm{~h}$, and a linear increase of voltage to $8000 \mathrm{~V}$ for $11 \mathrm{~h}$ and stand by $500 \mathrm{~V}$ for the second dimension). After the first dimension, all the strips were placed in equilibration buffer (0.05 M Tris-HCl, pH 8.8; 6 M urea; 30\% glycerol; 2\% (w/v) SDS; containing $1 \%(\mathrm{w} / \mathrm{v})$ DTT) and were slowly shaken for $15 \mathrm{~min}$. The strips were then incubated for another $15 \mathrm{~min}$ in the equilibration buffer with $2.5 \%(\mathrm{w} / \mathrm{v})$ iodoacetamide without DTT. The second dimension was conducted on $12.5 \%$ SDS-PAGE gels using the Ettan DALTsix system. After electrophoresis, the gels were silver stained by following the method of Mortz et al. (2001) and Gharahdaghi et al. (1999). Images were captured by ImageScanner III and spots were quantitatively analyzed using ImageMaster 2D Platinum 7.0. For all the matched spots, only protein spots with significant changes of at least 1.5 -fold, and deemed significant by Student's $t$-test at a level of $95 \%$ were accepted as differentially expressed proteins.

In gel digestion was performed according to Katayama et al. (2001). After being completely dried, the samples were re-suspended with $5 \mu \mathrm{L}$ of $0.1 \%$ TFA followed by mixing in $1: 1$ ratio with a saturated solution of $\alpha$-cyano-4-hydroxy-trans-cinnamic acid in 50\% acetonitrile (Shevchenko et al., 1996). One microliter of mixture was analyzed by

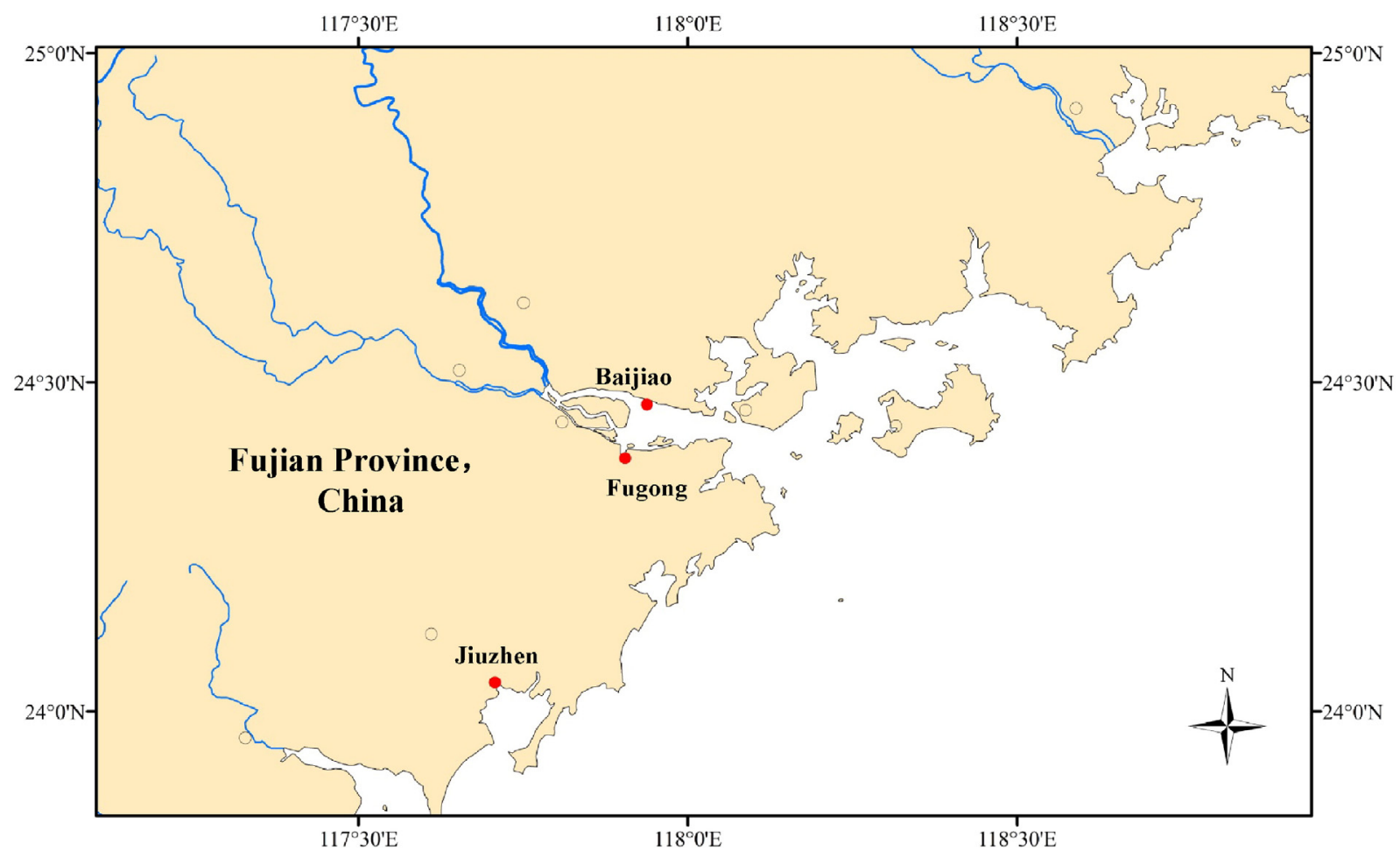

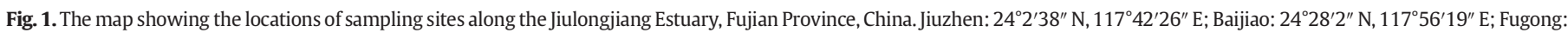
$24^{\circ} 22^{\prime} 58^{\prime \prime} \mathrm{N}, 117^{\circ} 54^{\prime} 13^{\prime \prime} \mathrm{E}$. 
Table 1

Metal/metalloid concentrations in hepatopancreas tissues from oysters Crassostrea hongkongensis sampled from three estuarine sites (JZ, BJ and FG).

\begin{tabular}{lccc}
\hline \multirow{2}{*}{$\begin{array}{l}\text { Metal/metalloid } \\
\text { concentration }(\mu \mathrm{g} / \mathrm{g}\end{array}$} & \multicolumn{3}{c}{ Sampling site } \\
\cline { 2 - 4 } $\mathrm{dw})^{\mathrm{a}}$ & $\mathrm{JZ}$ & $\mathrm{BJ}$ \\
\hline $\mathrm{Cr}$ & $0.5 \pm 0.2$ & $18.4 \pm 1.7^{* *}$ & $17.3 \pm 2.7^{* *}$ \\
$\mathrm{Mn}$ & $23.8 \pm 11.6$ & $65.0 \pm 36.1$ & $50.9 \pm 27.4$ \\
$\mathrm{Fe}$ & $302.6 \pm 158.9$ & $1821.5 \pm 993.0^{* *}$ & $550.3 \pm 181.6$ \\
$\mathrm{Co}$ & $0.7 \pm 0.3$ & $3.0 \pm 0.3^{* *}$ & $1.4 \pm 0.3^{*}$ \\
$\mathrm{Ni}$ & $1.3 \pm 0.6$ & $11.4 \pm 0.8^{* *}$ & $7.6 \pm 2.2^{* *}$ \\
$\mathrm{Cu}$ & $207.9 \pm 83.0$ & $5052.7 \pm 1961.7^{* *}$ & $2516.0 \pm 1738.6^{* *}$ \\
$\mathrm{Zn}$ & $3972.3 \pm 862.3$ & $8015.7 \pm 3146.0^{*}$ & $7739.0 \pm 4081.1$ \\
$\mathrm{As}$ & $11.8 \pm 1.8$ & $26.7 \pm 2.4^{* *}$ & $15.3 \pm 3.4$ \\
$\mathrm{Ag}$ & $1.3 \pm 0.6$ & $9.0 \pm 2.8^{* *}$ & $2.2 \pm 1.1$ \\
$\mathrm{Cd}$ & $4.7 \pm 0.7$ & $18.2 \pm 1.6^{* *}$ & $23.4 \pm 5.3^{* *}$ \\
$\mathrm{~Pb}$ & $2.2 \pm 0.4$ & $5.4 \pm 1.2^{* *}$ & $3.8 \pm 0.7^{* *}$ \\
\hline
\end{tabular}

${ }^{*}(P<0.05)$ and ${ }^{* *}(P<0.01)$ mean the significant differences of metal concentrations between clean (JZ) and metal pollution sites (BJ or FG) (Student's $t$-test).

a Data are shown as mean \pm standard deviation $(n=5)$. Values are presented as $\mu \mathrm{g} / \mathrm{g}$ dry weight.

an ABI 4800 MALDI-TOF/TOF Plus mass spectrometer (Applied Biosystems, Foster City, USA), data were acquired in a positive MS reflector using a CalMix5 standard to calibrate the instrument (ABI4800 Calibration Mixture). Both the MS and MS/MS data were integrated and processed using the GPS Explorer V3.6 software (Applied Biosystems, USA) with default parameters. Proteins were successfully identified based on $95 \%$ or higher confidence interval of their scores in the MASCOT V2.4 search engine (Matrix Science Ltd., London, U.K.). The following parameters were used in the search: NCBInr Metazoa (Animals) (2,861,494 sequences) database; trypsin as the digestion enzyme; one missed cleavage site; partial modifications of cysteine carbamidomethylation and methionine oxidization; no fixed modifications; 0.15 Da for precursor ion tolerance and 0.25 Da for fragment ion tolerance. Individual ions scores $>40$ indicate identity or extensive homology $(P<0.05)$.

The oyster tissue samples were dried to the constant weights and then digested in concentrated $\mathrm{HNO}_{3}$ at $80{ }^{\circ} \mathrm{C}$ for $12 \mathrm{~h}$, after which a clear liquid was obtained. Metal concentrations in the samples were determined by inductively coupled plasma mass spectrometry (ICP-MS, Agilent 7700x). Appropriate internal standards (Sc, Ge, In, Bi) were selected to correct the sensitivity drift and matrix effect. A quality control sample was repeatedly measured after every 10 samples. The recovery of the analyzed metals from the standard reference material (SRM $1566 \mathrm{~b}$, oyster tissue) was within $10 \%$ deviation from the certified values except $\mathrm{Cr}$, of which the certified concentration was not available. Metal concentrations were expressed as mean \pm standard deviation (S.D.). All the data of metal concentrations were subjected to principal component analysis with autoscaling and Student's $t$-test. A $P$ value $<0.05$ was considered significant. Statistical analysis was performed using Minitab software (Version 15, Minitab Inc. PA, USA).

The hepatopancreas tissue of marine bivalves is the most important organ for metal accumulation and detoxification. The concentrations $(\mu \mathrm{g} / \mathrm{g}$ dry weight) of ten metals $(\mathrm{Cr}, \mathrm{Mn}, \mathrm{Fe}, \mathrm{Co}, \mathrm{Ni}, \mathrm{Cu}, \mathrm{Zn}, \mathrm{Ag}, \mathrm{Cd}$ and $\mathrm{Pb}$ ) and one metalloid (As) in hepatopancreas from the oysters $C$. hongkongenesis collected from clean (JZ) and metal contaminated (BJ and FG) sites are summarized in Table 1 . To discern metal contamination situations, principal component analysis (PCA) were conducted to summarize the differences between different sampling sites, using the metal/metalloid concentrations as variables (Fig. 2). The biplot containing samples (oyster samples from the sampling sites) and variables (ten metals and one metalloid) is shown in Fig. 2, with the first two principal components (PCs) interpreting $81.6 \%$ of the variance from the original data set of metal concentrations in oyster hepatopancreas tissues. Visibly, these three groups of samples from JZ, BJ and FG sites were clearly separated along PC1 axis, which demonstrated the significant differences of tissue metal concentrations between the samples from the three sampling sites. Overall, along PC1 axis, the oyster samples from both $\mathrm{BJ}$ and FG contained higher average levels of $\mathrm{Cr}, \mathrm{Co}, \mathrm{Ni}$ and $\mathrm{Cu}$ than those from JZ site. Specifically, the metals/metalloid including $\mathrm{Cu}$, $\mathrm{Fe}, \mathrm{Co}, \mathrm{Pb}, \mathrm{Ag}$ and $\mathrm{As}$, were distributed in the cluster of samples from BJ site, suggesting that the samples from BJ site contained the highest average concentrations of these six metals/metalloid, with statistical significances (Table 1). The samples from FG contained the highest concentrations of $\mathrm{Cd}$ as shown in Table 1 .

Simply to compare the severity of metal pollution, an equation suggested by Liu and Wang (2012) was used to evaluate the integrated metal contamination:

Integratedmetalcontamination $=\sum_{i=0}^{m} C_{\text {contaminated }}^{i}-C_{\text {clean }}^{i .}$

where $C_{\text {contaminated }}$ is the concentration of the $i$ th metal/metalloid in a contaminated oyster, and $C_{\text {clean }}^{i}$ is a reference value for the $i$ th metal/ metalloid in an uncontaminated one. The reference was determined from the clean JZ oysters. And $\mathrm{m}$ is the number of all metals/metalloid measured in oyster tissue samples, i.e., $\mathrm{m}=11$ in this work. Calculation indicated that the oysters sampled from BJ site were the most severely contaminated ones because of the massive contribution from the very high tissue concentrations of $\mathrm{Cu}$ and $\mathrm{Fe}$ in oyster hepatopancreas.

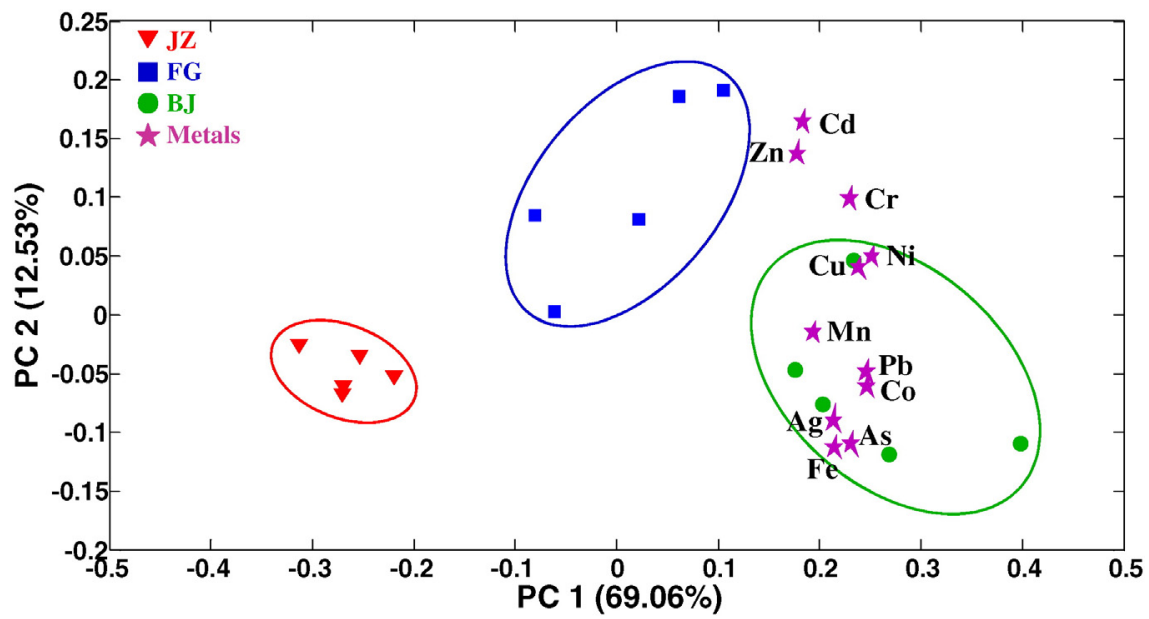

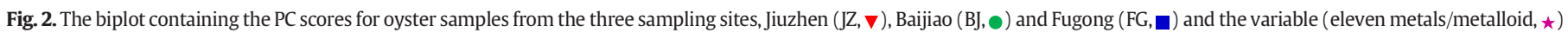
contributions for the clustering of oyster samples. 
Proteomic responses induced by metal pollution were determined by 2-DE-based proteomics in oyster hepatopancreas (Fig. 1). Approximately, 1000 protein spots were resolved in the 2-DE gels from the hepatopancreas of oysters $C$. hongkongensis. A total of 24 spots resolved in 2 -DE gels were differentially expressed $(>1.5$ folds, $P<0.05)$ in the oyster samples from both BJ and FG sites. Fig. 1 shows the differential protein spots in hepatopancreas of oyster $C$. hongkongensis sampled from BJ and FG sites compared with those from the reference site, JZ. All the differentially expressed proteins in all three biological replicates of silverstained gels were analyzed by MALDI-TOF/TOF mass spectrometry. The information of these proteins is summarized in Table 2.

In the oyster samples from BJ site, 22 proteins were differentially expressed, including 19 down-regulated and 3 up-regulated proteins. These proteins were basically related to oxidation-reduction process, metabolism, cytoskeleton, protein synthesis, chaperones, ion homeostasis, antioxidant system, signal transduction and transport. Only 7 proteins were significantly differentially expressed in the oyster samples from FG site, including 4 down-regulated and 3 up-regulated proteins. Among these 7 proteins, 5 proteins (SH3 domain-binding glutamic acid-rich-like protein 3, cofilin, actin, $78 \mathrm{kDa}$ glucose regulated protein and mammalian ependymin-related protein 1) were common in the oyster samples from both BJ and FG sites.

SH3 domain-binding glutamic acid-rich-like protein belongs to a new family of highly conserved small proteins related to thioredoxin superfamily which is involved in the control of redox dependent processes (Mazzocco et al., 2002). The structural features of alpha-crystallin B suggest that this protein is a small stress protein related to small heat shock protein family, while the $78 \mathrm{kDa}$ glucose regulated protein is another stress protein belonging to the $70 \mathrm{kDa}$ heat shock protein family. Evidences indicated that the heat shock proteins are responsive to heavy metal-induced oxidative stress (Fontaine et al., 2003). Peroxiredoxin, an antioxidant enzyme reducing hydrogen peroxide $\left(\mathrm{H}_{2} \mathrm{O}_{2}\right)$ and alkyl hydroperoxides treatments, regulates peroxide-mediated signaling cascades, while superoxide dismutase catalyzes the dismutation of superoxide into oxygen and hydrogen peroxide (Fujii and Ikeda, 2002). These two proteins are also responsive to oxidative stress. Cytochrome $b 5$ is involved in the cytochrome P450 monooxygenase reaction which is related to the oxidative stress induced by xenobiotics, such as $\mathrm{Cd}$ and $\mathrm{Cu}$ (Zhang et al., 2012). These 6 altered antioxidant proteins indicated the oxidative stress induced by metal pollution in oysters $C$. hongkongensis from BJ site. Among these 6 proteins, only SH3 domainbinding glutamic acid-rich-like protein and $78 \mathrm{kDa}$ glucose regulated protein were similarly altered in the oyster samples from FG site, which suggested that the metal pollution in FG site induced less severe oxidative stress in oysters. This finding is consistent with the less severe metal pollution in FG site, as mentioned above.

Actin is an abundant cytoskeletal protein that is a component of microfilaments in cells (Puerto et al., 2011). Both F-actin-capping protein and twinfilin are actin-binding proteins that are involved in the regulation of actin dynamics (Hartmann et al., 1989; Matzavinos and Othmer, 2007). Actin-depolymerizing factor is one of the actin cytoskeletonmodulating proteins, while cofilin promotes actin polymerization and defines the direction of cell motility (Allen et al., 1997; Ghosh et al., 2004). These proteins are all directly involved in cytoskeletal structure. Myosin regulatory light chains are regulators in the myosin contractile activity related to muscle contraction (Serwe et al., 1993). The tubulin-specific chaperones function as a tubulin assembly machine, marrying the $\alpha$ - and $\beta$-tubulin subunits into a tightly associated heterodimer (Tian and Cowan, 2013). The significant alterations of these seven cytoskeleton-related proteins (actin, F-actin-capping protein, twinfilin, actin-depolymerizing factor, cofilin, myosin regulatory light chains and tubulin-specific chaperone A) confirmed the cellular injury in oysters induced by metal pollution in BJ site. In numerous previous studies, some of these proteins such as actin, actin-depolymerizing factor, myosin regulatory light chain and F-actin-capping protein, were responsive to environmental stressor (e.g., arsenic, salinity, tetrabromobisphenol
A)-induced oxidative stress in animals (Wu et al., 2013b; Ji et al., 2013). In this work, these altered proteins confirmed the oxidative stress and subsequent cellular injury in cytoskeleton induced by metal pollution in oysters collected from BJ site.

Guanine nucleotide binding proteins, also known as $\mathrm{G}$ proteins, are involved in signaling pathways (Clapham and Neer, 1993). Recent studies demonstrated that $\mathrm{G}$ proteins may be critical for the stress responses, such as bacterial challenges (Clapham and Neer, 1993; Wu et al., 2013c). In marine mussel Mytilus galloprovincialis, one $\mathrm{G}$ protein was altered in response to bacterial challenges (Wu et al., 2013c). Cathepsin L played a major role in protein degradation of various physiological and

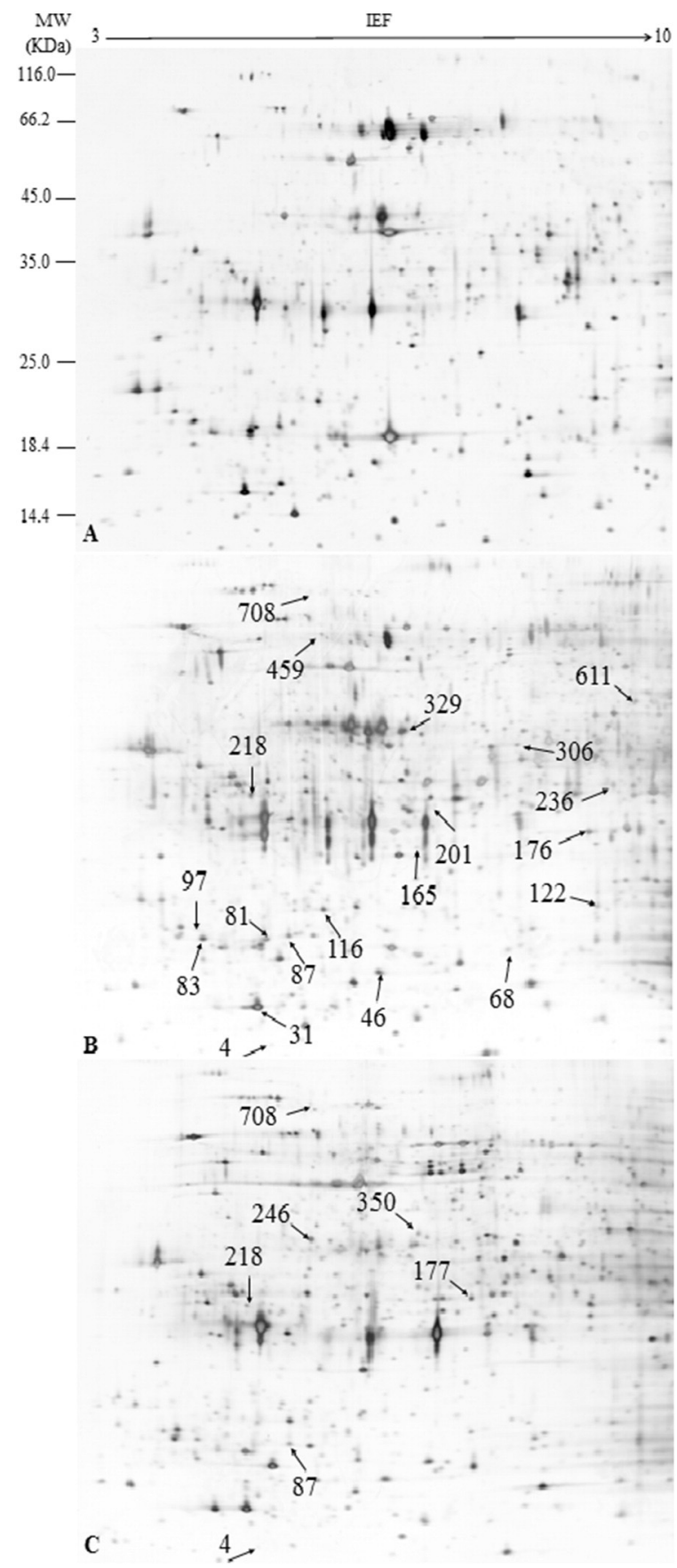

Fig. 3. Representative 2-DE images with dissolved protein spots from hepatopancreas tissues of oysters Crassostrea hongkongensis were submitted to isoelectric focusing on 4 7 IPG strips $(24 \mathrm{~cm})$ followed by electrophoresis on 12.5\% SDS-PAGE. Gels were stained by silver stain. Gels (A, B and C) of oyster samples are from (A) JZ, (B) BJ and (C) FC sites, respectively. The protein spots observed in all three biological replicates were analyzed by MALDI-TOF/TOF mass spectrometry. 
pathological processes and is a lysosomal cysteine protease involved in immune responses (Dorts et al., 2011). Ribosomal proteins perform the crucial function of protein biosynthesis and have been also recognized as immunogenic proteins (Ruszczyk et al., 2008). In bivalves and gastropods, the shell is mainly formed by $\mathrm{CaCO}_{3}$ crystals. The calcium regulation is an important process for the shell formation, as well as other physiological processes including immune-defense mechanisms (Nikapitiya et al., 2010). Both EF-hand domain-containing protein and ependymin-related protein are involved in calcium homeostasis and have been found to be immune responsive in marine bivalves. The down-regulation of these two proteins indicated the immune stress induced by metal pollution in oysters from BJ site, combined the altered guanine nucleotide binding protein, cathepsin L and $40 \mathrm{~S}$ ribosomal protein. In our previous study, cathepsin L was similarly down-regulated in the gills of clam Ruditapes philippinarum exposed to arsenate (Wu et al., 2013b). Interestingly, the arsenic concentration was significantly high in the hepatopancreas of oysters $C$. hongkongensis collected from BJ site, which implied that cathepsin L might be the protein biomarker of arsenic pollution.

Adipophilin is an adipocyte differentiation-related protein and is proposed as a general marker for the lipid load of non-adipogenic cells (Heid et al., 1998). Fatty acid-binding protein in adipocyte is a small molecular-weight protein that has a high binding affinity for long-chain fatty acids. It is shown to coordinate the lipid responses in cells and plays an important role in fatty acid metabolism by transporting fatty acids from cell membrane to mitochondria for oxidation (Kleine et al., 1992). ATP synthase is responsible for the production of ATP for energy supply. Therefore the altered adipophilin, fatty acid-binding protein and ATP synthase implied the disturbance in lipid and energy metabolism induced by metal pollution in oysters from BJ site. Ferritin has two functions, iron detoxification and iron storage. This protein plays a vital role in the cellular homeostasis as the physiological source of iron for the cell by storing excess iron (Durand et al., 2004). In the oyster samples from BJ site, the very high concentration of Fe was observed (Table 1).

Table 2

List of protein spots that differentially expressed in oysters Crassostrea hongkongensis sampled from BJ and FG compared to those from JZ.

\begin{tabular}{|c|c|c|c|c|c|c|c|c|}
\hline Spot ID ${ }^{\mathrm{C}}$ & Protein name & Accession number $^{\mathrm{d}}$ & $\mathrm{MW} / \mathrm{Da}$ & $\mathrm{pI}$ & Protein score ${ }^{\mathrm{e}}$ & $\mathrm{SC}(\%)^{\mathrm{f}}$ & $\mathrm{PN}^{\mathrm{g}}$ & Fold changes $^{\mathrm{h}}$ \\
\hline \multicolumn{9}{|c|}{ Oxidation-reduction process } \\
\hline 4 & SH3 domain-binding glutamic acid-rich-like protein 3 & 405952131 & 10,705 & 5.06 & 169 & 31 & 3 & $\begin{array}{l}-7.46^{\mathrm{a}} \\
-7.48^{\mathrm{b}}\end{array}$ \\
\hline 81 & Cytochrome $b 5$ & 84619354 & 14,589 & 5.03 & 397 & 38 & 3 & $-1.71^{\mathrm{a}}$ \\
\hline \multicolumn{9}{|c|}{ Metabolism } \\
\hline 83 & ATP synthase subunit delta, mitochondrial & 405953462 & 18,396 & 5.19 & 38 & 5 & 1 & $-1.51^{\mathrm{a}}$ \\
\hline 236 & Cathepsin L & 405958751 & 36,510 & 6.11 & 38 & 3 & 1 & $-1.85^{\mathrm{a}}$ \\
\hline 459 & Adipophilin & 405954235 & 54,006 & 5.16 & 216 & 7 & 3 & $-1.77^{\mathrm{a}}$ \\
\hline \multicolumn{9}{|c|}{ Cytoskeleton } \\
\hline 41 & Actin-depolymerizing factor 6 & 297347132 & 15,677 & 5.83 & 859 & 66 & 4 & $-1.95^{\mathrm{a}}$ \\
\hline 87 & Cofilin & 405963691 & 18,605 & 4.92 & 147 & 9 & 1 & $\begin{array}{l}-3.07^{\mathrm{a}} \\
-1.67^{\mathrm{b}}\end{array}$ \\
\hline 97 & Myosin regulatory light chain sqh & 405964694 & 19,552 & 4.68 & 152 & 24 & 3 & $-1.58^{\mathrm{a}}$ \\
\hline 306 & F-actin-capping protein subunit alpha & 405951960 & 32,291 & 5.77 & 629 & 42 & 8 & $-1.54^{\mathrm{a}}$ \\
\hline 350 & Actin & 2564711 & 41,765 & 5.3 & 331 & 20 & 6 & $\begin{array}{l}1.67^{\mathrm{a}} \\
1.54^{\mathrm{b}}\end{array}$ \\
\hline 611 & Twinfilin-2 & 405968211 & 32,071 & 6.41 & 115 & 9 & 2 & $1.64^{\mathrm{a}}$ \\
\hline \multicolumn{9}{|c|}{ Protein biosynthesis } \\
\hline 46 & 40S ribosomal protein S12 & 405977575 & 14,900 & 5.79 & 369 & 32 & 3 & $-1.80^{\mathrm{a}}$ \\
\hline \multicolumn{9}{|c|}{ Chaperones } \\
\hline 68 & Tubulin-specific chaperone A & 405978204 & 12,774 & 5.71 & 298 & 30 & 2 & $-1.61^{\mathrm{a}}$ \\
\hline 201 & Alpha-crystallin B chain & 405961891 & 23,113 & 5.74 & 280 & 21 & 3 & $-2.09^{\mathrm{a}}$ \\
\hline 708 & $78 \mathrm{kDa}$ glucose regulated protein & 46359618 & 73,030 & 5.02 & 551 & 16 & 7 & $\begin{array}{l}4.08^{\mathrm{a}} \\
1.51^{\mathrm{b}}\end{array}$ \\
\hline 246 & Heat shock protein beta-1 & 405961832 & 27,685 & 5.27 & 127 & 6 & 1 & $-1.70^{\mathrm{b}}$ \\
\hline 116 & Ferritin GF1 & 324792249 & 19,958 & 5.15 & 461 & 32 & 3 & $1.89^{\mathrm{a}}$ \\
\hline \multicolumn{9}{|c|}{ Ion homeostasis } \\
\hline 165 & EF-hand domain-containing protein D2 & 405951006 & 23,011 & 5.3 & 73 & 7 & 2 & $-2.19^{\mathrm{a}}$ \\
\hline 218 & Mammalian ependymin-related protein 1 & 405968755 & 40,505 & 5.79 & 50 & 2 & 1 & $\begin{array}{l}-1.56^{\mathrm{a}} \\
-1.62^{\mathrm{b}}\end{array}$ \\
\hline \multicolumn{9}{|c|}{ Antioxidant enzymes } \\
\hline 122 & Peroxiredoxin-5, mitochondrial & 405974897 & 16,566 & 5.66 & 290 & 27 & 3 & $-1.92^{\mathrm{a}}$ \\
\hline 176 & Superoxide dismutase [Mn], mitochondrial & 405962293 & 25,137 & 6.55 & 407 & 27 & 3 & $-1.54^{\mathrm{a}}$ \\
\hline \multicolumn{9}{|c|}{ Signal transduction } \\
\hline 329 & Guanine nucleotide-binding protein subunit beta & 405963261 & 37,306 & 5.62 & 307 & 14 & 4 & $3.05^{\mathrm{a}}$ \\
\hline \multicolumn{9}{|c|}{ Transport } \\
\hline 31 & Fatty acid-binding protein, adipocyte & 405949998 & 14,928 & 5.03 & 598 & 51 & 4 & $-2.68^{\mathrm{a}}$ \\
\hline 177 & Endoplasmic reticulum protein ERp29 & 405975720 & 28,273 & 5.19 & 29 & 4 & 1 & $2.13^{\mathrm{b}}$ \\
\hline
\end{tabular}

a Identification of differentially expressed proteins in oyster Crassostrea hongkongensis hepatopancreas from BJ and FG, compared to oyster hepatopancreas from JZ (less polluted).

b Identification of differentially expressed proteins in oyster Crassostrea hongkongensis hepatopancreas from BJ and FG, compared to oyster hepatopancreas from JZ (less polluted).

c Assigned spot ID as indicated in Fig. 3.

d GI numbers in NCBInr database.

e Mascot score reported.

f Sequence coverage.

g Number of peptide sequences.

h Fold changes with significant changes $(>1.5$ folds and $P<0.05$ ) were calculated using ImageMaster 2D Platinum 7.0. 
Therefore the ferritin GF1 was significantly $(P<0.05)$ up-regulated in the oyster samples from BJ site, which suggested that ferritin GF1 could be used as a biomarker of Fe contamination in oysters.

For the oyster samples from FG site, actin, cofilin and ependymin-related protein 1 were similarly altered compared with those in the oyster samples from BJ site. These altered proteins confirmed oxidative and immune stress induced by metal pollution in the oyster samples from FG site. However, two proteins including heat shock protein beta-1 and endoplasmic reticulum protein (ERp 29) were uniquely altered in the oyster samples from FG site. Cells respond to environmental stressors including physical (e.g. heat) or chemical (e.g. heavy metals) impacts by increased transcription of genes encoding so called heat shock or stress proteins. Heat shock proteins are ubiquitous molecular chaperones that are involved in the defensive system, such as anti-oxidative system, as mentioned above (Ji et al., 2013). ERp29 is a ubiquitously expressed endoplasmic reticulum (ER) stress-inducible protein that executes protective action by binding to denatured or aggregated cellular proteins thereby facilitating their refolding (Mkrtchian et al., 1998). These two altered proteins suggested the cellular injury induced by metal pollution in the oysters from FG site, via differential metabolic pathways compared with those in the oysters from BJ site.

The Jiulongjiang Estuary in South China has been severely polluted by metals, which posed great risk on the coastal organisms. As shown by the accumulations of metals/metalloid in oyster hepatopancreas, the two sampling sites, BJ and FG, were polluted by several metals, including $\mathrm{Cr}, \mathrm{Co}, \mathrm{Ni}, \mathrm{Cu}, \mathrm{As}, \mathrm{Ag}, \mathrm{Cd}$ and $\mathrm{Pb}$. Especially, the oysters from $\mathrm{BJ}$ site were also contaminated by Fe and $\mathrm{Zn}$. In this work, we applied two-dimensional electrophoresis (2-DE)-based proteomics to the oysters Crassostrea hongkongensis from metal pollution sites to characterize the proteomic responses induced by metal pollution. Proteomic responses indicated that the oysters from BJ site were more severely contaminated than those from FG site, which was consistent with the higher integrated metal contamination value of BJ site. Basically, metal pollution induced cellular injuries, oxidative and immune stresses in oyster heapatopancreas from both BJ and FG sites via differential metabolic pathways. In addition, metal pollution in BJ site induced disturbance in energy and lipid metabolisms in oysters. Results indicated that cathepsin L and ferritin GF1 might be used as the biomarkers of As and Fe in oysters C. hongkongensis, respectively. This study demonstrates that proteomics is useful to characterize the biological effects induced by metal pollution.

\section{Acknowledgments}

This work was supported by a Key Project from NSFC (21237004), National Key Basic Research Program of China (2015CB453303) and Natural Science Foundation of Shandong Province (No. JQ201310).

\section{References}

Allen, M.L., Dobrowolski, J.M., Muller, H., Sibley, L.D., Mansour, T.E., 1997. Cloning and characterization of actin depolymerizing factor from Toxoplasma gondii. Mol. Biochem. Parasitol. 88, 43-52.

Campos, A., Tedesco, S., Vasconcelos, V., Cristobal, S., 2012. Proteomic research in bivalves: towards the identification of molecular markers of aquatic pollution. J. Proteomics 75 , 4346-4359.

Cappello, T., Maisano, M., D'Agata, A., Natalotto, A., Mauceri, A., Fasulo, S., 2013. Effects of environmental pollution in caged mussels (Mytilus galloprovincialis). Mar. Environ. Res. 91, 52-60.

Clapham, D.E., Neer, E.J., 1993. New roles for G-protein beta-gamma dimers in transmembrane signalling. Nature 365, 403-406.

Dorts, J., Kestemont, P., Dieu, M., Raes, M., Silvestre, F., 2011. Proteomic response to sublethal cadmium exposure in a sentinel fish species Cottus gobio. J. Proteome Res. 10, 470-478.

Durand, J.P., Goudard, F., Pieri, J., Escoubas, J.M., Schreiber, N., Cadoret, J.P., 2004. Crassostrea gigas ferritin: cDNA sequence analysis for two heavy chain type subunits and protein purification. Gene 338, 187-195.

Fontaine, J.M., Rest, J.S., Welsh, M.J., Benndorf, R., 2003. The sperm outer dense fiber protein is the 10th member of the superfamily of mammalian small stress proteins. Cell Stress Chaperones 8, 62-69.
Fujii, J., Ikeda, Y., 2002. Advances in our understanding of peroxiredoxin, a multifunctional, mammalian redox protein. Redox Rep. 7, 123-130

Gharahdaghi, F., Weinberg, C.R., Meagher, D.A., Imai, B.S., Mische, S.M., 1999. Mass spectrometric identification of proteins from silver-stained polyacrylamide gel: a method for the removal of silver ions to enhance sensitivity. Electrophoresis 20, 601-605.

Ghosh, M., Song, X., Mouneimne, G., Sidani, M., Lawrence, D.S., Condeelis, J.S., 2004. Cofilin promotes actin polymerization and defines the direction of cell motility. Science 304, 743-746.

Goldberg, E.D., Koide, M., Hodge, V., Flegal, A.R., Martin, J., 1983. United States musse watch - 1977-1978 results on trace metals and radionuclides. Estuar. Coast. Shelf Sci. 16, 69-93.

Hartmann, H., Noegel, A.A., Eckerskorn, C., Rapp, S., Schleicher, M., 1989. Ca ${ }^{2+}$-independent F-actin capping proteins. J. Biol. Chem. 264, 12639-12647.

Heid, H.W., Moll, R., Schwetlick, I., Rackwitz, H.R., Keenan, T.W., 1998. Adipophilin is a specific marker of lipid accumulation in diverse cell types and diseases. Cell Tissue Res. 294, 309-321

Hines, A., Oladiran, G.S., Bignell, J.P., Stentiford, G.D., Viant, M.R., 2007. Direct sampling of organisms from the field and knowledge of their phenotype: key recommendations for environmental metabolomics. Environ. Sci. Technol. 41, 3375-3381.

Ji, C., Wu, H., Wei, L., Zhao, J., Lu, H., Yu, J., 2013. Proteomic and metabolomic analysis of earthworm Eisenia fetida exposed to different concentrations of 2,2',4,4'tetrabromodiphenyl ether. J. Proteomics 91, 405-416.

Jones, O.A.H., Dondero, F., Viarengo, A., Griffin, J.L., 2008. Metabolic profiling of Mytilus galloprovincialis and its potential applications for pollution assessment. Mar. Ecol. Prog. Ser. 369, 169-179.

Katayama, H., Nagasu, T., Oda, Y., 2001. Improvement of in-gel digestion protocol for peptide mass fingerprinting by matrix-assisted laser desorption/ionization time-of-flight mass spectrometry. Rapid Commun. Mass Spectrom. 15, 1416-1421.

Kleine, A.H., Glatz, J.F., Van Nieuwenhoven, F.A., Van der Vusse, G.J., 1992. Release of heart fatty acid-binding protein into plasma after acute myocardial infarction in man. Mol. Cell. Biochem. 116, 155-162.

Knigge, T., Monsinjon, T., Andersen, O.-K., 2004. Surface-enhanced laser desorption/ionization-time of flight-mass spectrometry approach to biomarker discovery in blue mussels Mytilus edulis exposed to polyaromatic hydrocarbons and heavy metals under field conditions. Proteomics 4 (9), 2722-2727.

Liu, F., Wang, W.-X., 2012. Proteome pattern in oysters as a diagnostic tool for metal pollution. J. Hazard. Mater. 239-240, 241-248.

Luo, L., Ke, C., Guo, X., Shi, B., Huang, M., 2014. Metal accumulation and differentially expressed proteins in gill of oyster (Crassostrea hongkongensis) exposed to longterm heavy metal-contaminated estuary. Fish Shellfish Immunol. 38, 318-329.

Matzavinos, A., Othmer, H.G., 2007. Stochastic analysis of actin polymerization in the presence of twinfilin and gelsolin. J. Theor. Biol. 249, 723-736.

Mazzocco, M., Maffei, M., Egeo, A., Vergano, A., Arrigo, P., Di Lisi, R., Ghiotto, F., Scartezzini, P., 2002. The identification of a novel human homologue of the SH3 binding glutamic acid-rich (SH3BGR) gene establishes a new family of highly conserved small proteins related to thioredoxin superfamily. Gene 29, 233-239.

Mkrtchian, S., Baryshev, M., Matvijenko, O., Sharipo, A., Sandalova, T., Schneider, G. Ingelman-Sundberg, M., 1998. Oligomerization properties of ERp29, an endoplasmic reticulum stress protein. FEBS Lett. 431 (3), 322-326.

Mortz, E., Krogh, T.N., Vorum, H., Gorg, A., 2001. Improved silver staining protocols for high sensitivity protein identification using matrix-assisted laser desorption/ionization-time of flight analysis. Proteomics 1, 1359-1363.

Nikapitiya, C., De Zoysa, M., Whang, I., Kim, S.J., Choi, C.Y., Lee, J.S., Lee, J., 2010. Characterization and expression analysis of EF hand domain-containing calcium-regulatory gene from disk abalone: calcium homeostasis and its role in immunity. Fish Shellfish Immunol. 29, 334-342.

Puerto, M., Campos, A., Prieto, A., Cameán, A., de Almeida, A.M., Coelho, A.V., Vasconcelos, V., 2011. Differential protein expression in two bivalve species: Mytilus galloprovincialis and Corbicula fluminea: exposed to Cylindrospermopsis raciborskii cells. Aquat. Toxicol. 101, 109-116.

Rank, J., Lehtonen, K.K., Strand, J., Laursen, M., 2007. DNA damage, acetylcholinesterase activity and lysosomal stability in native and transplanted mussels (Mytilus edulis) in areas close to coastal chemical dumping sites in Denmark. Aquat. Toxicol. 84 50-61.

Regoli, F., 2000. Total oxyradical scavenging capacity (TOSC) in polluted and translocated mussels: a predictive biomarker of oxidative stress. Aquat. Toxicol. 50, 351-361.

Ruszczyk, A., Joerink, M., Guldenaar, C., Hermsen, T., Savelkoul, H.F., Wiegertjes, G.F., 2008 cDNA expression library screening and identification of two novel antigens: ubiquitin and receptor for activated $C$ kinase (RACK) homologue, of the fish parasite Trypanosoma carassii. Fish Shellfish Immunol. 25, 84-90.

Serwe, M., Meyer, H.E., Craig, A.G., Carlhoff, D., D'Haese, J., 1993. Complete amino acid sequence of the regulatory light chain of obliquely striated muscle myosin from earthworm Lumbricus terrestris. Eur. J. Biochem. 211, 341-346.

Shevchenko, A., Wilm, M., Vorm, O., Mann, M., 1996. Mass spectrometric sequencing of proteins from silver stained polyacrylamide gels. Anal. Chem. 68, 850-858.

Tan, Q.-G., Wang, Y., Wang, W.-X., 2015. Speciation of Cu and Zn in two colored oyster species determined by X-ray absorption spectroscopy. Environ. Sci. Technol. 49, 6919-6925.

Thompson, E.L., Taylor, D.A., Nair, S.V., Birch, G., Haynes, P.A., Raftos, D.A., 2011. A proteomic analysis of the effects of metal contamination on Sydney rock oyster (Saccostrea glomerata) haemolymph. Aquat. Toxicol. 103, 241-249.

Tian, G., Cowan, N.J., 2013. Tubulin-specific chaperones: components of a molecular machine that assembles the $\alpha / \beta$ heterodimer. Methods Cell Biol. 115, 155-171.

Wang, W.-X., Pan, K., Tan, Q., Luo, L., Simpson, S.L., 2014. Estuarine pollution of metals in China: science and mitigation. Environ. Sci. Technol. 48, 9975-9976. 
Weng, N., Wang, W.-X., 2014. Variations of trace metals in two estuarine environments with contrasting pollution histories. Sci. Total Environ. 485 - 486, 604-614.

Wu, H., Ji, C., Wei, L., Zhao, J., 2013a. Evaluation of protein extraction protocols for 2-DE in marine ecotoxicoproteomics. Proteomics 21, 3205-3210.

Wu, H., Liu, X., Zhang, X., Ji, C., Zhao, J., Yu, J., 2013b. Proteomic and metabolomic responses of clam Ruditapes philippinarum to arsenic exposure under different salinities. Aquat. Toxicol. 15, 91-100.
Wu, H., Ji, C., Wei, L., Zhao, J., Lu, H., 2013c. Proteomic and metabolomic responses in hepatopancreas of Mytilus galloprovincialis challenged by Micrococcus luteus and Vibrio anguillarum. J. Proteomics 94, 54-67.

Zhang, L., Liu, X., Zhao, J., Gan, J., Ke, C., You, L., Liu, D., Yu, J., Wu, H., 2012. Identification and expression profile of a new cytochrome P450 isoform (CYP414A1) in the hepatopancreas of Venerupis philippinarum exposed to benzo[a]pyrene, cadmium and copper. Environ. Toxicol. Pharmacol. 33, 85-91. 